\title{
Pattern of local participation in tourism supply business within Kisumu County and its implication on tourism economic impact on poverty
}

\author{
Amata Mwalo Mathias \\ Maseno University, Kenya \\ amatamwalo2014@yahoo.com
}




\title{
Pattern of local participation in tourism supply business within Kisumu County and its implication on tourism economic impact on poverty
}

\author{
Amata Mwalo Mathias \\ Maseno University, Kenya \\ amatamwalo2014@yahoo.com
}

Received: 14/5/2021 Revised: 26/6/2021 Accepted: 4/7/2021 DOI: https://doi.org/10.31559/IJHTS2020.2.1.4

\begin{abstract}
The purpose of the study was to establish pattern of local participation in tourism supply business and its implication on local poverty reduction. The specific objective of the study included finding out the key local commodities that are important driver of tourism backward linkage with local economy of Kisumu County, establish differences in the average score profile among local suppliers and find out the main dimension along which they are separated. The study adopted across sectional and correlation design in which stratified random sampling of 106 tourism enterprises from a target population of 266 enterprises was obtained. Self - administered questionnaires were distributed to managers and collected by researcher. The first, second and third objectives were analysed using descriptive statistics, MANOVA and descriptive discriminant analysis respectively. It was found out that while poultry products, fish and vegetables were main commodities in the trade between local suppliers and tourist industry, fish, beef, and detergent were the most consumed commodities. Secondly, suppliers were different in their mean score profile by the value and quality of their supply, promptness in their delivery of supplies and in the longevity in commercial relationship with the tourist industry. Lastly, the suppliers were separated significantly along two main dimensions: The first dimension was interpreted to be efficiency and effectiveness, being represented by high value of weekly supply and high rating on promptness in making deliveries. The second dimension was experience, which was indicated by suppliers' education level and their longevity in the commercial relation with the tourist industry. The key contribution of the study is the creation of understanding of the main commodities driving tourism backward linkage with local economy and the factors which confer competitive advantage among local traders of Kisumu County in tourist industry.
\end{abstract}

Keyword: Local Suppliers; Dimension of differentiation; Promptness; Competitive advantage; Commercial relationship.

\section{Introduction}

Poverty is a serious scourge in many marginal and rural areas of developing countries, yet it can be mitigated by adoption of strategies that raise income and living standards of the poor (Todaro \& Smith, 2015). The pattern of participation of the local poor people in tourism reflect structural constraints affecting optimal exploitation of tourism economic opportunities by the poor, the extent to which tourism development can impact on poverty, and the feasibility of sustainable tourism development in marginal destinations. A number of studies have been conducted on the factors affecting the extent of local participation in tourism. According to Beyer(2014), local participation is underpinned by two factors namely the extent to which local community wield significant influence and control over tourism development and management, and the significance of the proportion of tourism benefits appropriated by local community. The later interpretation applies in the context of current study.

A number of different ways of improving participation of local poor have been attempted, but with mixed outcomes. One of such attempts is the pro poor tourism model, which is actualized through policy adjustment 
aimed at increasing levels of tourist arrivals to a destination, encouraging backward linkage of tourism through high quality and diverse local product, which can induce tourists to spend, and ensuring that the poor local people receive a high proportion of tourist expenditure (Holden, 2013). However, the model has been discounted on four grounds: First, any form of tourism can be pro poor (Zhao, 2016). Secondly, the distinction between pro poor tourism and other forms of tourism such as community - based tourism, alternative tourism, and sustainable tourism is blurred (Zhao, 2016). Thirdly, current practices of pro poor tourism is biased heavily on direct effect on poverty, but ignoring secondary effect on poverty and wider dynamic effect on economy and growth (Zhao, 2016; Mitchell \& Ashley,2010). Lastly, pro poor is not easy to replicate without modification because the root cause of poverty depend on the unique context of each location (Zhao, 2016).

Like pro poor tourism, community - based tourism is an approach to planning and development of tourism based on assumption that sustainability of tourism depends on local community involvement (Mair, 2016). It adopts a bottom - up approach to tourism policy - making and development and its key utility has been the reduction of inequality and poverty in the community, enhancement of community empowerment, control and ownership of tourism enterprise by community members (Mair, 2016). However, the main weakness of community - based tourism is in its failure to acknowledge that structural differences among community membership and their different levels of empowerment and interested has effect on the quality of policy decisions affecting optimal management of tourism enterprise (Mair, 2016).

The literature on the impact of tourism on poverty is rich, but mixed with some contractions. The income composition of various households has been analysed and financial impact of tourism employment compared with other off - farm activities. The conclusion was that tourism employment offers no guarantee towards poverty reduction (Adiya, 2017). This finding confirmed the previous finding by Frenzel et al.(2015) that tourism is not efficacious in mitigating poverty, because tourism in all slum destinations are not under the control of local poor residents. On the contrary, a study carried out in Dullstroom in South Africa by Gareth and Christian (2016) established that tourism generate benefits through capacity building and economic empowerment of black women. It also creates social, political and psychological benefits in terms of mutual trust and enhanced cohesion, and improved esteem (Gareth \& Christian, 2016). Similarly, a study by Siggalen, Sasongko and Wiloso (2019) in Indonesia established the existence of community participation in terms involvement in decision making, but it was not explicit on extent to which economic benefits were shared with local community. Moreover, tourism contributed significantly to the living condition of city residents of Bad Reichenhall in Germany which was attributed to publication and implementation of result of participative events, low threshold access to participation, higher degree of information and successful design of participative events (Kantsperger, Thees \& Eckert, 2019). Similarly, the efficacy of tourism in poverty reduction can be enhanced by the active involvement of the local poor in tourism by influencing development which affect quality of their lives and, thus solve their problems (Gunawijaya \& Pratiwi, 2018). Moreover, it is enhanced by the adoption of community self mobilization strategies such as skill development in hospitality, financial assistance and encouraging entrepreneurship and cooperation among community members (Thesane,2019; Gunawijaya \& Pratiwi, 2018). Four similar studies have been conducted in Lesotho, in Tioman Island in Malaysia, in Western Kenya and in Murchison Falls Conservation Area in Uganda, to not only to establish how community can be involved in tourism, but also to find out factors limiting their participation, and how to enhance local participation in tourism management and entrepreneurship. Thetsane (2019) found out that consultation with local community of Lesotho in tourism policy formulation process and mainstreaming their collective voice in key decision making process was important. However, extent of local participation was not only undermined by socio economic variables such as education and employment status (Azman \& Yahaya, 2013), but also the level of awareness and limited skills and capacity (Kala \& Bagri, 2018, Ayorekire et al, 2017; Odege, 2014; Oketch et al, 2012).

\subsection{Theory of poverty}

The main reason for linking tourism sector with local economy is to enhance local economic impact and thus help reduce poverty. This theory is useful in understanding structural factors which affect local participation in tourism activities. Poverty is a condition of deprivation characterized by the inability to meet basic physiological needs and shelter, inability to exploit opportunities for self - development, inability to play a role as member of a community or society, and marginalization (Holden,2013). There are two main and broad theories of poverty: Geographical and socioeconomic theories of poverty. The former explain the distribution of poverty in space while the latter advance reasons why individuals or households live in poverty (Chimhowu, 2009).

According to Chimhowu (2009) geographical theory of poverty has got two main perspectives, namely the deterministic and possibility perspectives. While deterministic perspective attributes existence of poverty to the characteristics of the physical environment, possibility perspective advances the idea that the association between developmental decisions and poverty is influenced, but not determined by physical environment.

The socioeconomic theories of poverty include individual pathologies theory, culture of poverty narrative and structural causes of poverty. According to pathologies theory, which was discounted for its failure to recognize structural barriers which limit individual from exploiting opportunities, individual weaknesses such as 
laziness, mental or physical infirmities are responsible for individual situation (Chimhowu,2009). Last but not least, the culture of poverty narrative states that poverty is a product of social belief systems passed down to successive generation through socialization (Chimhowu, 2009). Lastly, 'structural causes' perspective explains poverty in terms of structural impediments within capitalist economy and political systems (Chimhowu, 2009). In summary, the foregoing theories are foundation upon which valuable insights on factors affecting local participation in tourism activities leading to stronger or otherwise economic linkage of tourism and local economy can be appreciated.

Though the literature is rich on factors affecting local participation in tourism activities, there is no enough information regarding the pattern of local participation and its implications on the reduction of extreme poverty in Kisumu County - Kenya. In order to fill the gaps, current study was guided by three key objectives: First, to analyse the local products which drive tourism backward linkage with local economy. Secondly, to establish the differences in average score profiles among local suppliers and third finding out the main dimension along which local suppliers are differentiated. A cross sectional and correlation design was adopted in which a random sample of 106 enterprises were drawn from a target population based on sampling frame got from Tourism Regulatory Authority. Self - administered questionnaires were used in the data collection. The first objective was achieved through descriptive statistics, the second objective was achieved through the adoption of multivariate analysis of variance and the third objective was achieved through descriptive discriminant analysis. The key finding from the study was that poultry products, fish and vegetables were main commodities in the trade between local suppliers and tourist industry, but fish, beef and detergent were the most consumed commodities. Secondly, suppliers were different in their mean score profile by the value and quality of their supply, promptness in their delivery of supplies and in the longevity in commercial relationship with the tourist industry. Lastly, the suppliers were separated significantly along two main dimensions: The first dimension interpreted to be efficiency and effectiveness, being represented by high value of weekly supply and high rating on promptness in making deliveries. The second dimension was experience, which was indicated by suppliers` education level and their longevity in the commercial relation with the tourist industry. It was concluded that the effectiveness and efficiency in the local supply business operations couple with experience in operating in the tourists industry are the key factors conferring local suppliers' competitive advantage in trade, but their narrow range of product traded with tourist industry constrains their ability to exploit maximum economic opportunities. The key contribution of the study is the creation of knowledge and understanding of the main commodities driving tourism backward linkage with local economy and the factors which confer competitive advantage among local traders of Kisumu County in tourist industry

\section{Methodology}

\subsection{Study Area}

Kisumu County has a total area of 2,085.9 square kilometres with a population size of 968,909 , it is generally warm throughout the year with temperature which range from $20^{\circ} \mathrm{C}$ to $35^{\circ} \mathrm{C}$, and its humidity is high throughout the year. According to Kisumu County Annual Development Plan for Fiscal Year 2019/2020, Kisumu County is one of 47 counties created by the constitution of 2010 and it is the main gateway to the rest of Africa Great Lake region. In terms of development profile, Kisumu County Gini Coefficient was 0.430 in the year 2013(Kenya National Bureau of Statistics [KNBS] \& Society for International Development [SID], 2013). Thus, distribution of income expenditure in the County deviates from a perfect equal distribution (KNBS\&SID, 2013). Additionally, Kisumu County recorded Human Development Index (HDI) of 0.52 which is similar to national index, but far from the ideal index of 1.00 (National Council for Population and Development [NCPD],2017).

Fortunately, Kisumu County is a promising tourists` destination in the western circuit, as it is endowed with diverse tourist attractions which include wildlife, culture and spectacular physical features (Communication, Economic Planning and Development Executive Committee, 2013). It has an international Airport through which the County can directly get international tourists (Ministry of East Africa Affairs, Commerce and Tourism, 2015), and it has recently experienced massive investment in infrastructure and tourists facilities (Communication, Economic Planning and Development Executive Committee, 2018).

However, the full potential of tourism resources has not been exploited (Babu, Haghiri \& Oketch 2012) and the County has continued to register high rates of poverty levels (World Bank, 2016), thereby putting a lot of questions on the role of tourism in County development. The main economic activities in the county for local residents are fishing, agriculture and industrial activities based in urban areas(NCPD,2017), but fishing and subsistence agriculture face a bleak future due to overfishing, water hyacinth menace, inappropriate fishing methods and waste disposal (Communication, Economic Planning and Development Executive Committee, 2018). Furthermore, the County has a growing youthful population majority of whom are unemployed, without entrepreneurial skill and whom have been identified in the County Integrated Development Plan 2013 - 2017 as a threat to development (Communication, Economic Planning and Development Executive Committee, 2013). 
According to Sector Plan for Tourism 2013 -2017 involvement of the youth in tourism activities at County level economically empower them and help reduce insecurity (Ministry of East Africa Affairs, Commerce and Tourism, 2013). But the ability of Kisumu County hospitality industry to absorb unemployed youths has been undermined by its very low occupancy rate (Kenya Bureau of Statistics, 2012). Moreover, local participation rate in tourism activities is insignificant (Oketch et al. 2012; Odege, 2014). Ventures which are run by local people at both Kit Mikayi and Got Ramogi are ineffective because of limited capacity among the people (Misiko, 2013).

Therefore, indications of weak tourism backward linkage with micro and small business sector within the County include inadequate entrepreneurial skills and capital amongst youthful population (Ministry of East Africa Affairs, Commerce and Tourism,2013), limited economic prospects in hospitality industry and poor or inadequate output from agricultural activities (Kenya National Bureau of Statistics,2010). As a result of limited capital and entrepreneurial skills among local people, their participation in tourism related activities is low (Babu, et al. 2012; Odege, 2014).

As far as this current study is concerned, the county was clustered into three regions namely central business districts which included Kisumu main town and areas extending to Milimani, Nyalenda, Kilimani, Kachok, Polyview, Kibuye, and Kamas. Outskit of Kisumu town constituted Nyalenda, Kondele, Migosi, Mamboleo, Airport Area, Nyawita, Obunga and Dunga. Kisumu rural encompassed Kanyakwar, Kanyamedha, Kogony, Kisian, Ojola, Maseno, Kolenyo, Nyamasaria, Awasi, Ahero, Katito, Pap Onditi and beyond.

\subsection{Research philosophy and design}

The ontology of positivism provided the overall framework for the study. Positivism is a philosophical stance that mirrors the one adopted in natural science (Veal, 2018). The study was based on factual data which existed in the records of tourism enterprises and which were collected using self - administered questionnaires. Hypotheses, which guided the study, were formulated before data collection and were, later, tested using factual collected data. The phenomena under study differences in local suppliers mean profile and their characteristics in relation to level of participation in tourism activities was explained using such models as descriptive discriminant analysis and path model, which were developed by the researcher based on the previous studies and theory.

\subsection{Target Population, Sampling Technique and Sample Size}

The study was bases 266 Tourism Enterprises which were not only duly registered by Tourism Regulatory Authority but also operated within Kisumu County and have been in operation for at least one year. The enterprises included hotels, guest houses, restaurants and clubs. Stratified proportionate random sampling was adopted in selecting 106 enterprises from the 266 enterprises (Kothari 2014). The sample size was determined using Fisher`s formulae, which is given as $n=\frac{\mathbf{z 2 \times P \times ( 1 - P )}}{\mathbf{e} 2}$

Where $\mathrm{P}$ is the proportion of population with desired characteristics, $\mathrm{e}$ is the margin of error and $\mathrm{Z}$ is quantile on a standard normal distribution corresponding to probability of 0.95 . The sample size was adjusted using the formulae $\frac{N \times n}{N+n}$, because the size of the target population was less than 10,000. Therefore, the sample size used in the current study was 106, and it was based on the population of 266 Enterprises, a confidence level of $95 \%$ and a margin of error of 7.5\% (Cohen, Marrison and Mansion 2007).

\subsection{Data Collection}

\subsubsection{Instrument}

Self- administered questionnaire was distributed physically by the researcher to 110 managers of tourism enterprises in the morning hours and collected back either in the evening or the following day in order to maximize response rate. Quantitative and qualitative data pertaining to tourism enterprises and their suppliers were captured by the instrument. However, out of 110 questionnaires 106 randomly selected complete questionnaires were used in the analysis. The questionnaire included questions which required the respondent to state rate weekly procurements made from local suppliers, key commodities supplied, supplier level of education and the length of time in months that the respondent has been in commercial relationship with local supplier. It also included questions requiring the respondent rating of local supplier on five criteria namely quality of supply, pricing of supplies, promptness in delivery of supplies, variety of supplies and number of suppliers engaged with on a weekly basis. The key variables that were measured were groups of local suppliers which acted as a dependent variable. This is a categorical variable that was measured on a nominal scale. The local suppliers were grouped according to the frequency of weekly supply. Thus, there were three groups of local suppliers namely: suppliers whose weekly rate of supply was 4 times and below, the second group comprised of suppliers who made supplies at a weekly rate of between 5 and 7 times, and the third group who made a weekly supply rate of 8 times and above. There were five independent variables namely the value of weekly supply variable, promptness of supply delivery variable, quality of supplies variable, supplier education level variable and supplier longevity in commercial relation with tourist industry variable. The weekly supply value and supplier longevity in commercial 
relation variables were measured on a continuous scale, promptness and quality of supply variables were measured on Likert scale of 1 through 10 points, with I indicate very low and 10 indicating very high. Lastly, supplier education level variable was measured on ordinal scale of 1 through 4 , with 1 indicating primary level, 2 indicating secondary level, 3 indicating college and 4 indicating university. The rate of consumption of the various commodities supplied by local traders was measured by asking the consumers to rate their monthly consumption of the same on a Likert scale of 1 through 7, with 1 being lowest and 7 being highest. All the scales of measurements were originated by the researcher.

\subsubsection{Validity and Reliability of the instrument}

While face validity refers to the apparent reflection of the content of the concept by a measure (Bryman and Bell 2011), content validity is the extent to which adequate coverage of the investigative questions has been achieved by a measure (Cooper and Schindler 2014). Both face and content validity are assessed by the judgment of panel of experts (Bryman and Bell 2011; Cooper and Schindler 2014). Accordingly, the questionnaire used in the current study was screened for face and content validity by a panel of experts in tourism and economics department of Maseno University during proposal presentation stage. Reliability, based on internal consistency, was determined by correlating a set of 23 questionnaire items measuring similar concept. According to Bryman and Bell (2011), internal reliability is applied to a measure with multiple indicators and Cronbach`s alpha ranging from 0.80 to 0.70 is mostly acceptable levels. Similarly, set of items in the questionnaire of current study were assessed for reliability and based on 94 valid observations, the Cronbach`s alpha was 0.820 and it was deemed satisfactory.

\subsection{Data Analysis}

\subsubsection{Differences in Local Participation in Tourism Activities}

The first objective was to establish significant differences in the average score profile amongst groups of local suppliers based on given discriminatory variables and the second objective was to establish the main dimensions along which they were separated. Multiple descriptive discriminant analysis was used to both find out the significance in the average score profiles and main dimensions of discrimination among the local suppliers. The suppliers were grouped according to the frequency of weekly supply which included 4 times a week and below, 5 and 7 times a week, and 8 times a week and above.

\subsubsection{Specification of Discriminant Analysis Function}

The discriminating variables included in the discriminant function were those deemed to be significant indicators of extent of tourism backward linkage with local economy by determining the level of local suppliers' activities in tourism sector, as they loaded significantly on local purchase ratio variable.

Discriminant Score ${ }_{i}=\beta_{0}+\beta_{1 X_{i 1}}+\beta_{2 X_{i 2}}+\beta_{3 X_{i 3}}+\beta_{4 X_{i 4}}+\beta_{5 X_{i}}$, where $\beta_{\mathrm{i}}$ are the discriminant weights and $\mathrm{x}_{\mathrm{ij}}$ are observations made on the various discriminating variables.

$\mathrm{X}_{\mathrm{i} 1}$ - are observations on weekly supply value variable.

$\mathrm{X}_{\mathrm{i} 2}$ - are observations on rate promptness variable.

$\mathrm{X}_{\mathrm{i} 3}$ - are observations on supply quality rating variable.

$\mathrm{X}_{\mathrm{i} 4}$ - are observation on supplier education level.

$\mathrm{X}_{\mathrm{i} 5}$ - are observations on longevity in commercial relationship between local supplier and tourist industry.

\section{Results}

\subsection{Analysis of the key products traded by local suppliers and their rate of consumption}

Figure 1 below indicates the main product traded between local suppliers and the tourist industry of Kisumu County. According to the Figure, beverage, beef and detergent account for $9 \%$ of all key commodities supplied by local suppliers, poultry product accounted for $13 \%$, and fish and vegetables, each accounted for $21 \%$. It is apparent that fishery and agriculture are the key sectors which drive tourism backward linkage with local economy of Kisumu County.

Result from Table 1 shows that the overall industrial consumption rate is significant and above average for vegetable, fish, poultry products, beef, beverage, and detergent. Moreover, according result in Table 2, consumption rate in hotels exceed that in guest houses, restaurant, and clubs across all types of commodities. Of all the commodities, fish and detergent is consumed at the highest and lowest rate respectively in hotels. The rate of consumption of beverage and beef is highest and lowest respectively among guest houses. Lastly, rate of consumption of detergent and fish is highest and lowest among restaurants and clubs. 


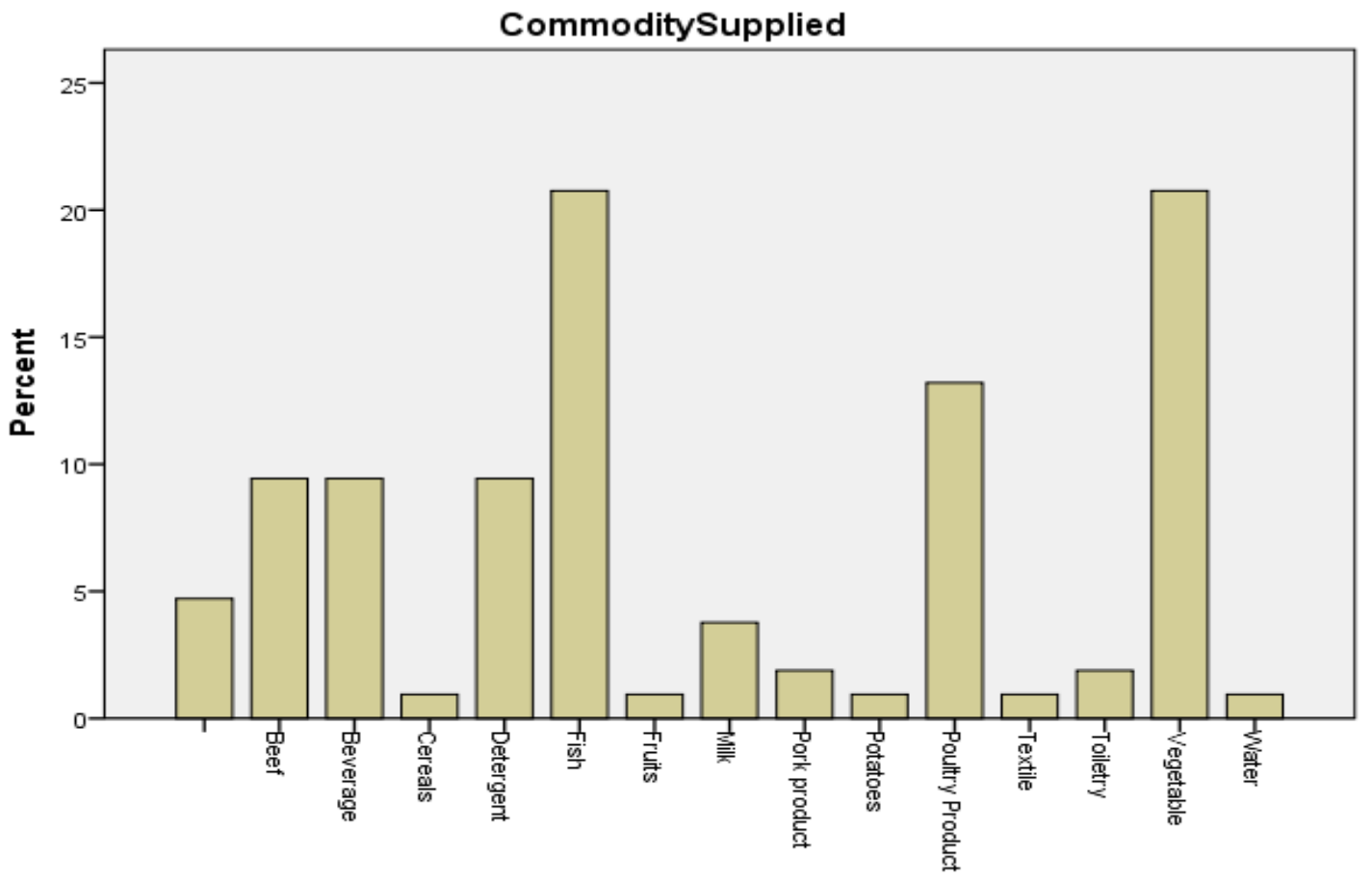

CommoditySupplied

Figure (1): Main products Supplied by Local Traders

Table (1): Overall Industrial Consumption Rating

\begin{tabular}{lcrrr}
\hline & & & \multicolumn{2}{c}{ 95\% Confidence Interval } \\
\cline { 3 - 5 } Consumption Rating & Mean & Std. Error & .192 & Lower Bound \\
\hline Rating Vegetable consumption & 4.436 & .201 & 4.056 & 4.113 \\
Rating Fish consumption & 4.511 & .203 & 3.990 & 4.817 \\
Rating Poultry consumption & 4.392 & .187 & 3.442 & 4.910 \\
Rating Beef Consumption & 3.812 & .193 & 4.474 & 4.183 \\
Rating Beverages consumption & 4.856 & .192 & 5.238 \\
Rating Detergent consumption & 4.160 & 4.542 \\
\hline
\end{tabular}

Table (2): Consumption Rating by Types of Tourism Enterprises

\begin{tabular}{|c|c|c|c|c|c|}
\hline \multirow[b]{2}{*}{ Consumption Rating } & \multirow[b]{2}{*}{ Enterprise Type } & \multirow[b]{2}{*}{ Mean } & \multirow[b]{2}{*}{ Std. Error } & \multicolumn{2}{|c|}{ 95\% Confidence Interval } \\
\hline & & & & Lower Bound & Upper Bound \\
\hline \multirow[t]{3}{*}{ Rating Vegetable consumption } & Hotel \& lodge & 5.392 & .265 & 4.866 & 5.918 \\
\hline & Guest House & 3.250 & .358 & 2.540 & 3.960 \\
\hline & Restaurant \& Club & 4.667 & .364 & 3.944 & 5.389 \\
\hline \multirow{3}{*}{ Rating Fish consumption } & Hotel \& lodge & 5.765 & .278 & 5.214 & 6.316 \\
\hline & Guest House & 4.250 & .375 & 3.507 & 4.993 \\
\hline & Restaurant \& Club & 3.519 & .382 & 2.762 & 4.276 \\
\hline \multirow[t]{3}{*}{ Rating Poultry consumption } & Hotel \& lodge & 5.020 & .280 & 4.464 & 5.576 \\
\hline & Guest House & 3.750 & .378 & 3.000 & 4.500 \\
\hline & Restaurant \& Club & 4.407 & .385 & 3.643 & 5.171 \\
\hline \multirow[t]{3}{*}{ Rating Beef Consumption } & Hotel \& lodge & 4.725 & .258 & 4.213 & 5.238 \\
\hline & Guest House & 2.786 & .349 & 2.094 & 3.477 \\
\hline & Restaurant \& Club & 3.926 & .355 & 3.222 & 4.630 \\
\hline \multirow[t]{3}{*}{ Rating Beverages consumption } & Hotel \& lodge & 5.176 & .267 & 4.648 & 5.705 \\
\hline & Guest House & 4.429 & .360 & 3.715 & 5.142 \\
\hline & Restaurant \& Club & 4.963 & .366 & 4.236 & 5.690 \\
\hline \multirow[t]{3}{*}{ Rating Detergent consumption } & Hotel \& lodge & 4.451 & .266 & 3.924 & 4.978 \\
\hline & Guest House & 4.214 & .359 & 3.503 & 4.926 \\
\hline & Restaurant \& Club & 3.815 & .365 & 3.090 & 4.540 \\
\hline
\end{tabular}

\subsection{The analysis on average score profiles of Local Suppliers.}

The mean for the five discriminant variables across the three groups is indicated below in the Table 1 and the significance of group means differences are shown in the Table 2 below. From the results there was significant group means differences in weekly supply value ( $F$ value $=6.788$, $p$ value $=0.002$ ), rating on promptness in supply delivery $(\mathrm{F}$ value $=6.353$, $\mathrm{p}$ value $=0.003)$, rating on quality of supplies $(\mathrm{F}$ value $=3.605, \mathrm{p}$ value $=0.031)$ and longevity in commercial relationship $(F$ value $=4.829$, $p$ value $=0.010)$.

Results in Table 2 indicate that local suppliers who made 8 and more supplies per week sold supplies valued at Kshs 16,888, were most favourably rated (8.842) in terms of making prompt deliveries of the highest quality 
(8.5), and were most experienced in supply business, having been in the business for $261 / 2$ months. Suppliers who made between 5 and 8 supplies per week sold, on average, supplies valued at Kshs 13,780, were rated second most favourably (8.147) in terms of making deliveries promptly of second highest quality(7.824), but had the least experience in supply business of 14 months. Lastly, local suppliers who made 4 and less supplies per week and had 19 months experience in the supply business sold, on average, Kshs 6,756 worth of supplies, were favourably rated high on promptness in making deliveries (7.441) whose quality were highly rated (7.559). However, there were no significant differences amongst groups of local suppliers on the account of level of education.

Table (3): Supplier Groups Descriptive Statistics

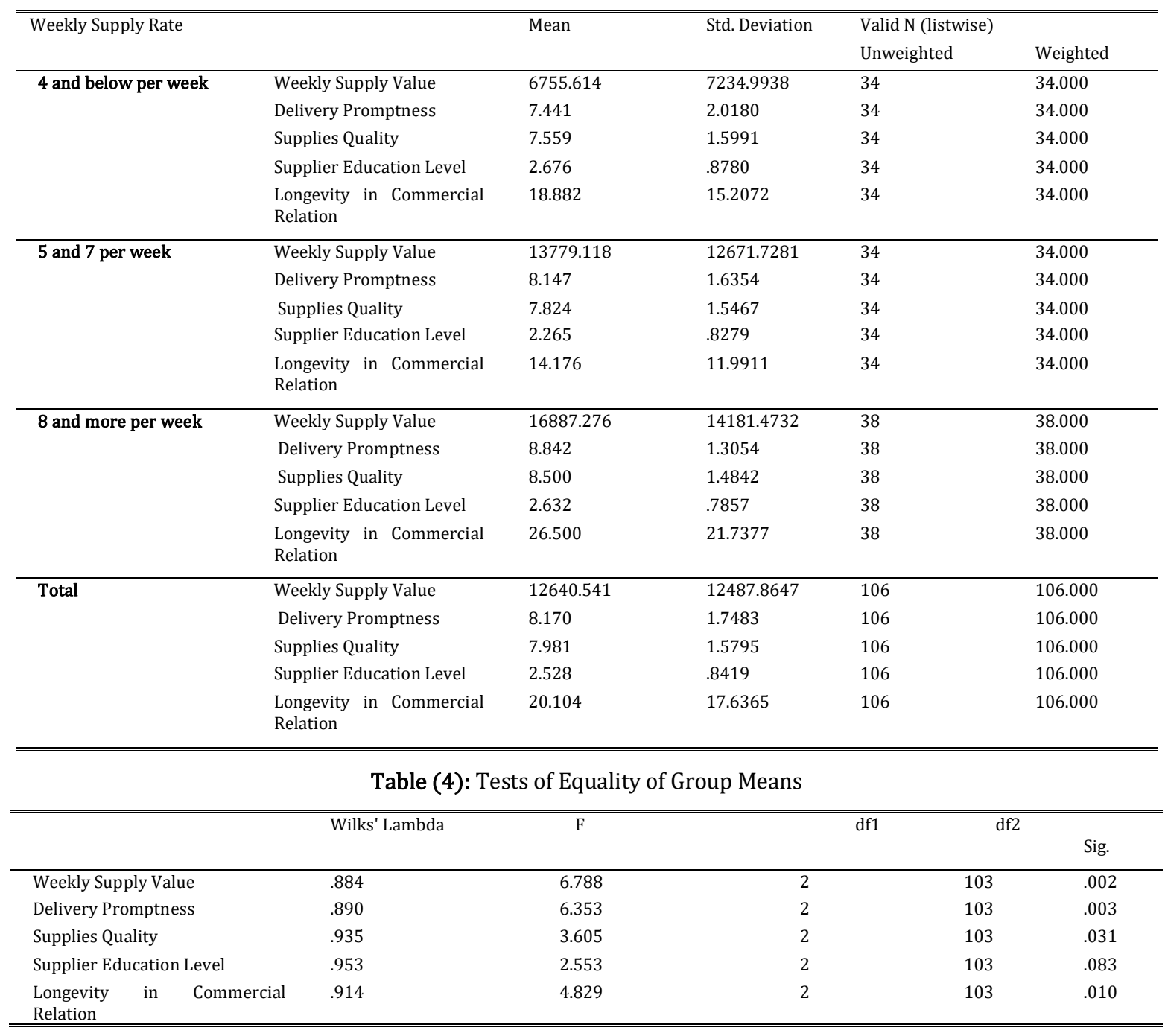

\subsection{Characteristics differentiating Local Suppliers and dimensions of their separation.}

The expected number of dimensions along which the three groups would be differentiated was two and this was statistically confirmed in Table 5 and Table 6 below. From the result in Table 5 the local suppliers were differentiated by the first significant discriminant function $(\chi 2$ value $=36.638$, $\mathrm{p}$ value $=0.000$ ) and second discriminant Function $(\chi 2$ value $=11.055, \mathrm{p}$ value $=0.026)$. From result in Table 6 variance of composite scores in the first discriminant function account for $22.4 \%$ of Between Group Variance and the discriminant function itself account for $71.4 \%$ of all Between Group Variance. The variance of composite scores in the second discriminant function account for $10.4 \%$ of Between Group Variance and the discriminant function itself accounts for $28.6 \%$ of total Between Group Variance. Therefore, the further uniqueness of the current study compared with the previous studies lie in insight that it generated regarding the dimension of differentiation among local suppliers in their participation in tourism activities: the three groups of local suppliers were separated to a greater extent along the first dimension, and to a lesser extent along the second dimension. 


\begin{tabular}{|c|c|c|c|c|c|}
\hline \multicolumn{6}{|c|}{ Table (5): Eigen values } \\
\hline Function & Eigenvalue & \% of Variance & Cumulative $\%$ & Correlation & Canonical \\
\hline 1 & .288 & 71.4 & 71.4 & .473 & \\
\hline 2 & .116 & 28.6 & 100.0 & .322 & \\
\hline
\end{tabular}

Table (6): Wilks' Lambda

\begin{tabular}{llllll}
\hline \hline Test of Function(s) & Wilks' Lambda & Chi-square & Df & Sig. & .000 \\
\hline 1 through 2 & .696 & 36.638 & 10 & .026 & \\
2 & .896 & 11.055 & 4 & .626 \\
\hline \hline
\end{tabular}

The following Table 7 indicates the association between the two significant discriminant functions and discriminating variables. According to the standardized canonical discriminant coefficient indicated in Table 7, value of weekly supply and rating on promptness in supply delivery load heavily on first discriminant function as opposed to rating on supply quality, supplier education level and longevity in commercial relationship. The high composite score on this first discriminant function is associated with high values in weekly supply, favourable rating on promptness in supply delivery, positive longevity in commercial relationship with tourism enterprises, but negative rating on quality of supplies and lower supplier education level. The second discriminant function is associated with longer length of time in commercial relationship with tourism enterprises, higher education level of supplier, low rating on supply quality but low rating in supply delivery promptness and decreasing value of weekly supply.

Table (7): Standardized Canonical Discriminant Function Coefficients

\begin{tabular}{lll}
\hline & \multicolumn{2}{c}{ Functions } \\
\hline & 1 & 2 \\
\cline { 2 - 3 } Weekly Supply Value & .739 & -193 \\
Rate Promptness & .694 & -.158 \\
Rate Supplies Quality & -.049 & .012 \\
Supplier Education Level & -.060 & .656 \\
Longevity in Commercial Relation & .217 & .752 \\
\hline \hline
\end{tabular}

The coordinate of group means for the three categories of supplier is indicated below in Table 6. Figure 2 indicates actual positions of group centroids in a space defined by the two significant discriminant functions. According to the discriminant plane, local suppliers who made 5 and 7 supplies per week have been separated from those who made 4 and less supplies per week, and those who made 8 and more supplies per week along the second discriminant function. However, the second discriminant function had not separated suppliers who made 4 and less supplies per week from those who made 8 and more supplies per week. Lastly, suppliers who made 8 and more supplies per week and those who made 4 and fewer supplies per week scored higher on the second discriminant function than suppliers who made 5 and 7 supplies per week.

The First Discriminant Function has successfully separated the three groups of suppliers. Generally, suppliers who made 8 and more supplies per week score highest on the discriminant function followed by group of local suppliers who made 5 and 7 supplies per week. Suppliers who made 4 and fewer supplies per week scored the lowest on the first discriminant function.

Since significant loadings on functions are deemed to be those of at least 0.3 (Finch and Laking, 2008), First discriminant function is defined by high value of weekly supply and high rating on promptness in making deliveries, both of which represent effectiveness and efficiency. The second discriminant function is defined by high education level amongst suppliers and sustainability in commercial relationship with tourism enterprises, representing experience.

Table (8): Functions at Group Centroids

\begin{tabular}{lcc}
\hline \hline Weekly Supply Rate & \multicolumn{1}{c}{ Functions } & 2 \\
\hline & 1 & .225 \\
& & -.488 \\
4 and below per week & -.683 & .235 \\
5 and 7 per week & .010 & \\
8 and more per week & .603 & \\
Unstandardized canonical discriminant functions evaluated at group means & \\
\hline \hline
\end{tabular}




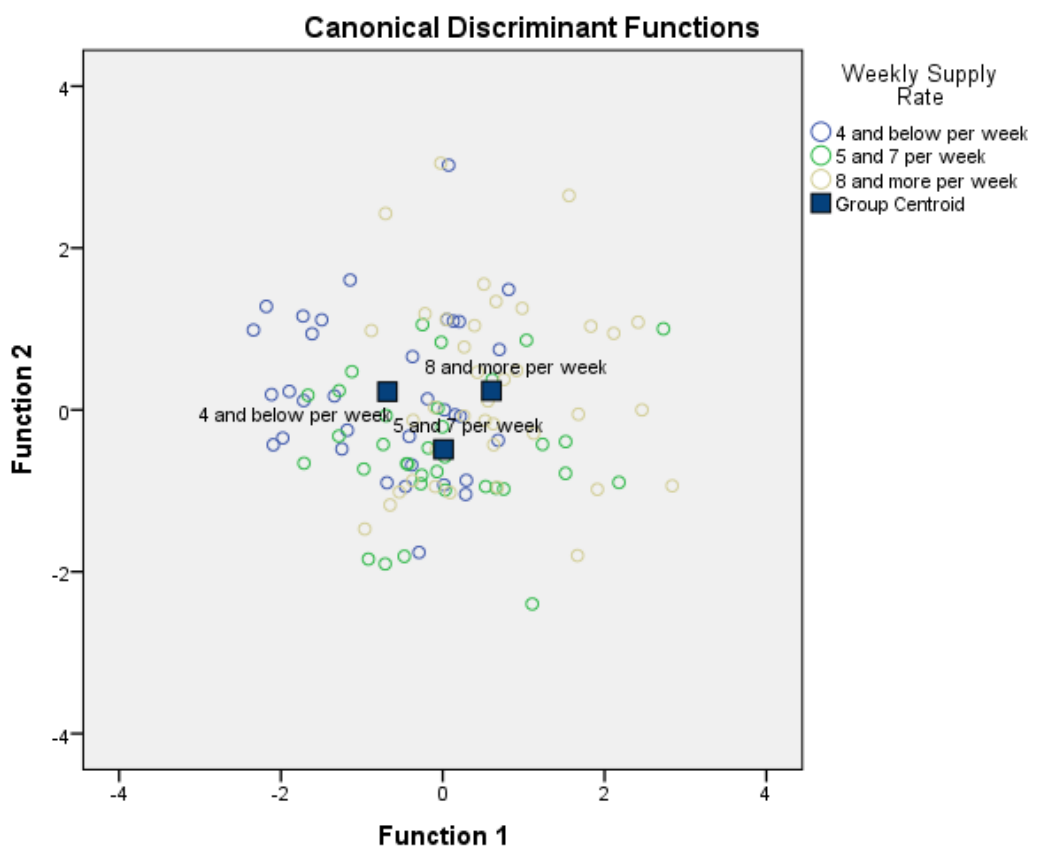

\section{Discussion}

Figure (2): Groups of suppliers in discriminant plane

The purpose of the study was to establish pattern of local participation in tourism supply business and its implication on tourism impact on local poverty reduction at the grass root level. It has been established that fishery and agriculture are the key sectors which drive tourism backward linkage with local economy of Kisumu County. The overall industrial consumption rate is significant and above average for vegetable, fish, poultry products, beef, beverage and detergent. Also, Consumption rate of local produce in hotels exceed that in guest houses, restaurant and clubs across all types of commodities. Of all the commodities supplied by local traders, fish and detergent is consumed at the highest and lowest rate respectively in hotels. The rate of consumption of beverage and beef is highest and lowest respectively among guest houses. Lastly, rate of consumption of detergent and fish is highest and lowest respectively among restaurants and clubs. Therefore, contrary to the previous finding by Adiya (2017) and Frenzel (2015) that tourism has no significant impact on poverty, the current study finds that tourism has some positive effect on the economy dominated by local people. The study has also established that local traders are different on four main performance criteria namely value of weekly supply, promptness with which they respond to orders from the tourist industry, quality of their supplies and longevity in commercial relationship with the tourist industry. In particular, local traders who respond most promptly to orders from tourist industry, who have the greatest length of commercial relationship with tourist industry and supply their goods most frequently in a week realize the highest revenue from sales. This finding is a new contribution to the previous finding on factors affecting community participation in tourism as was established by such scholars as Azman and Yahaya (2013), Kala and Bagri (2018) and Ayorekire et al, (2017). Apart from differences on average score profile among local traders, the study also established that the traders were differentiated more along the first dimensions namely effectiveness and efficiency than second namely experience which is indicated by value of supplies and promptness in their delivery to customers. This finding is a significant deviation from the previous studies by Gunawijawa and Praiti(2018), Adiya(2017), and Christian (2016) whose studies were biased towards the constraints of local community participation in tourism as opposed to factors differentiating local traders - members of local community already involved in tourism activities.

The findings presents key implications: First, since fishery and agriculture are the main commodities which drive tourism linkage with local economy and that hotels out - perform other establishment in the local procurement, the impact of tourism on poverty can be significant if the two sectors are not only streamlined and local traders in the sectors are supported to improve their sales mostly to the hotel industry, but also if the local economy dominated by local people is diversified. Also, the expansion of hotel industry can enhance tourism effects on the local economy. Lastly, the narrow range of product traded limits local traders from exploiting maximum economic opportunities in the tourism economy. Therefore, the impact of tourism on poverty may not be maximized if tourism is not robustly linked with the diversified local economy. This confirms the deterministic perspective in the theory of poverty which attributes existence of poverty to the characteristics of the physical environment (Chimhowu, 2009) and consistent with observation by Beyer (2014) that real local participation in tourism is partly determined by significance of economic benefits expropriated by local community. 
Secondly, local suppliers with optimal productive capacity and who have stable and long term relationship with tourist industry are in the most advantageous position to appropriate optimal economic benefits from tourism business activities. This confirms the previous finding by Bwasiri (2014) when he established that limited experience in tourism business undermined local participation in tourism. Therefore, tourism economic impact on poverty is significant on local economy in which local suppliers have businesses of adequate sizes whose productive capacity can meet the industrial demand on an efficient and sustainable basis. Lastly, local suppliers who wish to succeed in tourism supply business need to be supported to build distinctive capabilities around quality management, efficiency, and awareness of dynamic needs of the tourist industry.

The limitation of the study is that it focused mostly on hotels, restaurants, clubs, and guest houses. Thus, the findings are biased against such other tourism enterprises such as tour companies, airlines, and apartments. Also, the study was based on Kisumu County and the findings may not be generalized to other counties other than Kisumu County. Lastly, the study relied mostly on questionnaires as the only data collection instrument thus missing additional information that would have been gathered had the questionnaires been used together with in - depth interviews.

The future research should explore more on factors which enhance sale of local produce and sustainability of commercial relationship with the tourism industry in general and large luxury hotels in particular based on logistic regression and structural equation modelling.

\section{Conclusion}

In a nut shell, the purpose of this study was to establish the pattern of local participation in tourism activities and its implication on poverty reduction by finding out the key commodities which characterize local supply businesses, establishing the average score profile among local traders and finding out the main dimensions along which local suppliers are differentiated. The study main contribution is in creating knowledge and understanding of the bases of local economy on which local poor people operate in Kisumu County. The study also revealed the criteria upon which local suppliers are different and the significant factors behind the differentiation of local suppliers.

Acknowledgement: The cooperation of Tourism Regulatory Authority, National Commission for Science and Technology, County government of Kisumu and Maseno University in the study is recognised and highly appreciated.

Conflict of Interest: There is not any conflict of interest whatsoever in the execution of the study ad in its research outcome.

\section{References}

1. Adiya, B. et al. (2017). Poverty alleviation Potential of Tourism Employment as an off - farm activity on the local livelihoods surrounding Kibale National Park, Uganda. Tourism and Hospitality Research, 17(1): 34 - 51, doi: $10.1177 / 1467358416634156$

2. Ayorekire, J., Mugiri, F., \& Obua, J. (2017). 'Factors affecting Local Participation in Tourism in Murchinson Fall Conservation Area - Uganda'. Journal of Environmental Science and Engineering. A, 6(4): 209 - 223, https://doi.org/10.17265/2162-5298/2017.04.005.

3. Azma, I., Mustapha, A., \& Yahaya, I. (2013). 'Barrier to Community Participation in Island Destinations - Malaysia'. Journal of Tourism, Hospitality and Culinary Art, 5(1): 102 - 124.

4. Beyer, M. (2014). Tourism Planning and Development Cooperation: A hand Book. Berlin: GIZ.

5. Bryman, A., and Bell, E., (2011). Business Research Methods. Great Clarendon Street, Oxford: Oxford University Press.

6. Bwasiri, E. (2014). Conflict Among Local People and Hunting Tourism Companies in Nothern Tanzania. In W. Cordula, \& W. Werner, International Handbook on Tourism and Peace (pp. 154 - 162). Austria: World Tourism Organization.

7. Chimhowu, A. (2009). Poverty. In R. Kitchin, \& N. Thrift, International Encyclopedia of Human Geography (pp. 408 - 414). Oxford,Uk: Elservier.

8. Cohen, L., Manion, L., \& Marrison, K. (2007). Research Methods in Education 6th Edition. London: Routledge.

9. Cooper, D., and Schindler, S.P., (2014). Business Research Method, Twelfth Edition. New York: McGraw - Hill Irwin

10. Communication, Economic planning and development executive committee. (2013). Kisumu County First County Integrated Development Plan 2013 -2017. Kisumu: Kisumu County Government.

11. Communication, economic planning and development executive committee. (2018). Kisumu County Second Integrated Development Plan 2018 - 2022. Kisumu: Kisumu County Governement. 
12. Frenzel, F., Koen,K., Steinbrink, M., \& Rogerson, M.C. (2015). Slum Tourism: State of the Art. Tourism Review International, 18(4): 237 - 252, https://doi.org/10.3727/154427215x14230549904017.

13. Gareth, B., and Christian, M.R. (2016). Inclusive Local Tourism Development in South Africa: Evidence from Dullstroom. Local Economy, 31(1-2): 264 - 281, https://doi.org/10.1177/0269094215623732.

14. Giannaki, E. (2014). The Role of Rural Tourism on Development of Rural Areas: Case Study of Cyprus. Romania Journal of Regional Science, 8(1): 38 - 53.

15. Gunawijaya, J \& Pratiwi, A. (2018). How Local Community Could Contribute to the Tourism Development in Rural Area? The Second International Conference on Vacational Higher Education (ICVHE) 2017 "The Importance of Advancing Vacational Education to Meet Contemporary Labor Demands". KnE Social Sciences, pp 826 - 834. Doi: 10.18502/kss.v3i11.2809.

16. Holden, A. (2013). Tourism, Poverty and Development. London: Routledge.

17. Kala,D., \& Bagri, C.S.,(2018). Barrier to Local Community Participation in Tourism Development: Evidence from Mountainous State Uttarakhand, India. Tourism, 66(3): 318 - 333.

18. Kantsperger,M., Thees, H., \& Eckert, C. (2019). Local Participation in Tourism Development - Roles of Non - Tourism Related Residents of the Alpine Destination Bad Reichenhall. Sustainability, 11(24):6947, https://doi.org/10.3390/su11246947.

19. Kenya National Bureau of Statistics. (2010). Economic Survey 2010. Nairobi: Government of Kenya.

20. Kenya National Bureau of Statistics. (2012). Economic Survey 2012. Nairobi: Government of Kenya.

21. Kenya National Bureau of Statistics(KNBS) and Society for International Development(SID). (2013). Exploring Kenya inequality: Pooling Apart or Pooling together? Nairobi: Kenya National Bureau of Statistics.

22. Koens, K. (2012). Competition, Cooperation and Collaboration: Business Relation and Power in Township Tourism. In F. Frenzel, K. Koens \& M. Steinbrink (Eds.), Slum Tourism: Poverty, Power and Ethics. London: Routledge.

23. Kothari, C.R. 2014. Research Methodology: Methods and Techniques, $2^{\text {nd }}$ Revised Edition. New Delhi: New Age International (P) Limited.

24. Misiko, A. (2013). Assessing Niche Tourism Potential at Kit Mikayi Sacred Site using Activity - based Segmentation: Towards Sustainable Tourism Product Diversification. Research on Humanities and Social Sciences, 3(22): 8 -18.

25. Ministry of East Africa Affairs, Commerce and Tourism (2013). Sector Plan for Tourism 2013 - 2017. Nairobi: Government of Kenya.

26. Mudimba, T., \& Tichaawa, T.M. (2017). Voices of Local Communities regarding their involvement in the Tourism Development Process in Victoria Falls, Zimbabwe. African Journal of Hospitality, Tourism and Leisure, 6(4): 1- 15. http//:www.ajhtl.com

27. National Council for Population and Development(NCPD). (2017). 2015 Kenya National Adolescence and Youth Survey. Nairobi: NCPD.

28. Odege, D. (2014). Factors influencing Community Participation in Cultural Tourism at Kit Mikayi in Kisumu County. Nairobi: University of Nairobi.

29. Oketch, R., Haghiri, M., \& Babu, P. (2012). “ Rural Tourism as a Sustainable Development Alternative: An Analysis with specific reference to Luanda, Kenya". Sustainability, Tourism and Environment in the shift of a Millenium.

30. Singgalen Y.A., Sasongko,G., \& Wiloso, P.G.,(2019). Community Participation in Regional Tourism Development: A case study of North Halmahera Regency - Indonesia. Insight into Regional Development, 1(4): 318 - 333, https://doi.org/10.9770/ird.2019.1.4(3).

31. Thetsane,R.,(2019). Local Community Participation in Tourism Development: The Case of Katse Villages in Lesotho. Anthens Journal of Tourism, 6(2): 123 - 139, doi:10.30958/ajt.

32. Todaro, P.M. and Smith, C.S. (2015). Economic Development. New York: Pearson Education Limited.

33. UNWTO (2014). Tourism Highlight, 2014 Edition. World Travel Organization.

34. Weaver, D., \& Lawton, L. (2014). Tourism Management. Austria: John Wiley and Sons Ltd.

35. World Travel and Tourism Council (2015). Travel and Tourism Economics Impact 2015 - Sub Sahara Africa. London: World Travel and Tourism Council.

36. World Bank (2014). Poverty Overview. Washington DC: World Bank.

37. World Bank. (2016). The World Bank Annual Report 2016. Washington DC: World Bank.

38. Veal, A. (2018). Research Methods for Leisure and Tourism. Harlow,UK: Pearson Education Limited. 